\title{
Internal States and Behavioral Decision-Making: Toward an Integration of Emotion and Cognition
}

\author{
Ann Kennedy, ${ }^{1}$ Kenta Asahina, ${ }^{3,5}$ Eric Hoopfer,${ }^{1,2,5}$ Hidehiko Inagaki, ${ }^{4,5}$ Yonil Jung, ${ }^{1,5}$ \\ Hyosang Lee, ${ }^{1,5}$ Ryan Remedios, ${ }^{1,5}$ and David J. Anderson ${ }^{1,2}$ \\ ${ }^{1}$ Division of Biology, California Institute of Technology, Pasadena, California 91125 \\ ${ }^{2}$ Howard Hughes Medical Institute, Pasadena, California 91125 \\ Correspondence: wuwei@caltech.edu
}

\begin{abstract}
Social interactions, such as an aggressive encounter between two conspecific males or a mating encounter between a male and a female, typically progress from an initial appetitive or motivational phase, to a final consummatory phase. This progression involves both changes in the intensity of the animals' internal state of arousal or motivation and sequential changes in their behavior. How are these internal states, and their escalating intensity, encoded in the brain? Does this escalation drive the progression from the appetitive/motivational to the consummatory phase of a social interaction and, if so, how are appropriate behaviors chosen during this progression? Recent work on social behaviors in flies and mice suggests possible ways in which changes in internal state intensity during a social encounter may be encoded and coupled to appropriate behavioral decisions at appropriate phases of the interaction. These studies may have relevance to understanding how emotion states influence cognitive behavioral decisions at higher levels of brain function.
\end{abstract}

Survival and reproduction are mediated by innate, goal-directed activities (LeDoux 2012; Sternson 2013), such as feeding, drinking, mating, fighting, and escape from a predator. Each such activity is characterized by its own complex collection of actions, ${ }^{6}$ modulated by sensory information from multiple modalities. Furthermore, these actions are often organized in a characteristic sequence or progression, from an initial appetitive or motivational phase, to a more directed investigative phase, to a final consummatory phase (Fig. 1A; Berridge 2004). For example, in the case of an agonistic encounter between conspecific males, the appetitive phase includes investigation to determine the sex and assess the relative size or strength of the opponent; this is often followed by threat displays and then finally overt attack or retreat (Miczek et al. 2007). This progression is also accompanied by an increasing risk of injury, illness, or death; therefore, such behavioral transitions involve cost-benefit decisions (Gillette et al. 2000; Hirayama et al. 2012).

Progression through these different phases of an aggressive or sexual encounter is typically associated with an escalating internal state of motivation, arousal, or drive (for concepts and definitions, see Berridge 2004; LeDoux 2012). The concept of drive has proven useful to behavioral neuroscience and fits with our intuitive experience of behavior - not as a sequence of independent motor acts, but as a continuous escalation of a single state (e.g., from annoyance to anger to rage). But it is difficult

\footnotetext{
${ }^{6}$ The word "activity" is used here operationally to describe an ongoing behavior, such as "aggression"; "action" is used to describe a specific motor program executed during that activity, such as biting (Anderson and Perona 2014).
}

to determine through observation alone whether drives are a component of neural computation, playing a causal role in the control of behavioral decisions, or simply epiphenomena. Konrad Lorenz formulated a "hydraulic" metaphor to explain how different behavioral actions might be successively released under the control of an escalating internal drive (or motivational) state, with different drives for different behaviors (Fig. 1B; Lorenz and Leyhausen 1973; Berridge 2004). Although this model invoked a causal role for the level of drive states in controlling transitions or "decisions" between different behaviors, it made no predictions as to how such a role might be implemented in neural hardware.

In a view complementary to Lorenz's Tinbergen proposed that behavioral decisions are made in a hierarchical manner: More generic choices between competing or "opponent" activities (e.g., to engage in fighting or mating) are made before more specific selections of a particular action (e.g., between a threat display and a bite) (Fig. 1C; Tinbergen 1950). He further suggested that each decision stage could be mediated by a group of mutually inhibitory "centers" in the brain, with successive decision stages connected in a feed-forward manner to form a behavioral decision tree (Tinbergen 1950, 1951).

Although Tinbergen's model is useful as a heuristic, it leaves open a number of important theoretical issues. First, it does not explain why different actions controlled by "third-level" command centers progress through a characteristic sequence during an escalating encounter nor suggest how such progressions might be controlled. Second, it does not distinguish whether the higher-order ("second-level") centers that control different activities (mating, fighting) exert some control over decisions be-

Present Addresses: ${ }^{3}$ The Salk Institute, La Jolla, California 92037. ${ }^{4}$ HHMI Janelia Research Campus, Ashburn, Virginia 20147.

${ }^{5}$ These authors are listed alphabetically.

Copyright (C) 2014 Cold Spring Harbor Laboratory Press; all rights reserved; doi: 10.1101/sqb.2014.79.024984

Cold Spring Harbor Symposia on Quantitative Biology, Volume LXXIX 
A

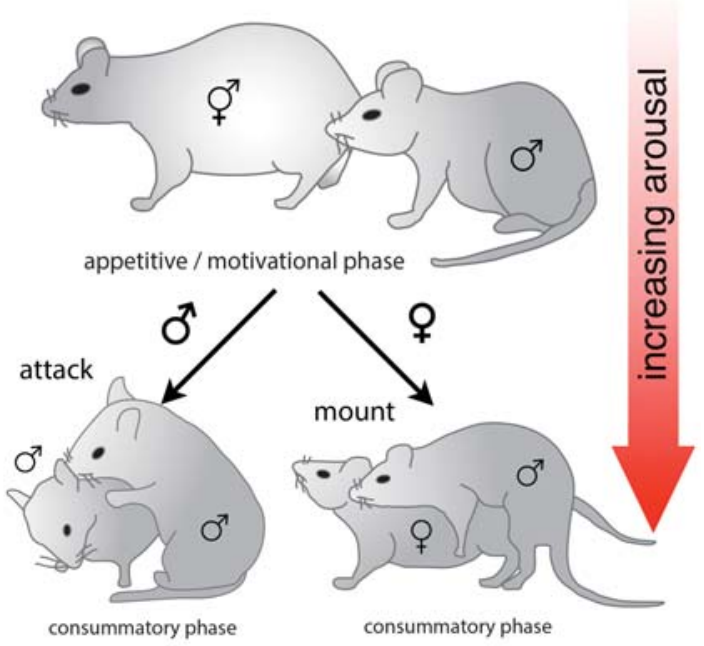

B
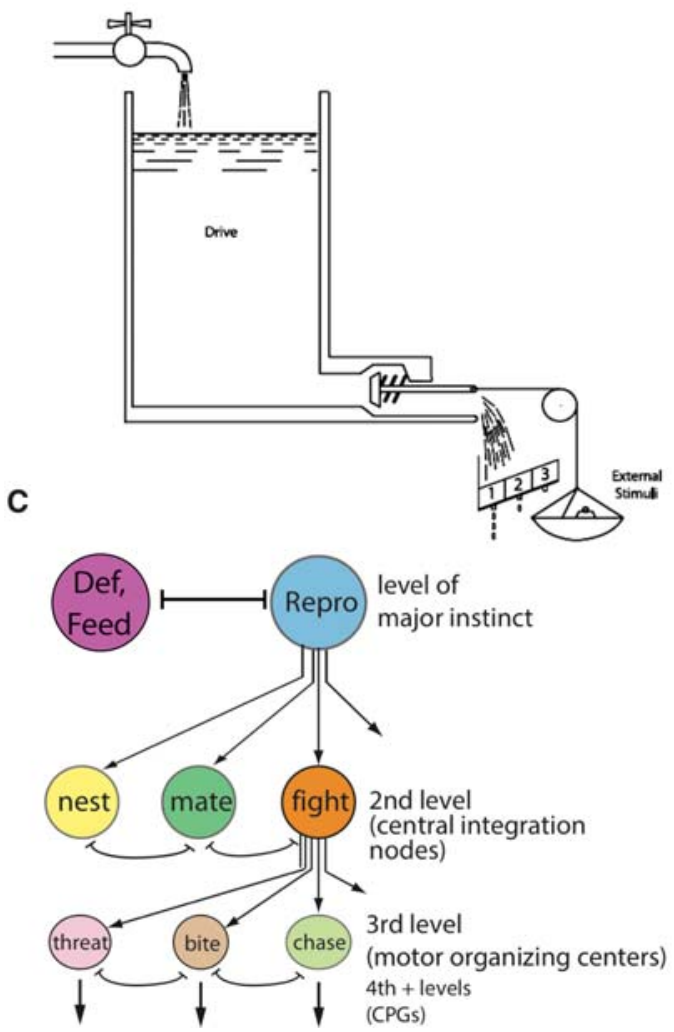

Figure 1. (A) Progression from investigative to consummatory phases of social behavior. $(B)$ Lorenz's "hydraulic" metaphor for the control of behavior by internal drive states. $(C)$ Tinbergen's hierarchical model for behavioral decisions (Tinbergen 1950). ( $B$, Reprinted from Berridge 2004, with permission from Elsevier; $C$, modified from Anderson 2012.).

tween actions dictated by third-level command centers, or rather simply act as a switch or gate, that permits such activities to occur. Finally, it does not integrate this hierarchical view of behavioral decision-making with any sort of internal drive or arousal states during a social interaction or consider whether and how such states might contribute to the control of such progressive decisions.

The question of how escalating internal states influence decisions between competing behaviors or actions, while fascinating, has not been widely investigated at the level of neural mechanism. To approach this subject, a number of basic questions need to be addressed. How are behavioral states, such as arousal or motivation, encoded or instantiated in the brain (Berridge 2004; Pfaff et al. 2005)? How is the escalation of these states implemented? Are these states behavior-specific, or generic (Devidze et al. 2006)? At what node(s) in a decision hierarchy or network do such states exert their influence on behavioral decisions? How are these influences exerted mechanistically? And is the level or intensity of such escalating states important in the actual control of behavioral decisions?

Here, we summarize our efforts to begin to approach these questions, in the context of innate behaviors, with a focus on aggression. We have pursued parallel studies in the mouse and in the vinegar fly Drosophila melanogaster in an effort to identify underlying evolutionarily conserved principles of neural circuit function across species. Our hope is that these studies may also prove relevant to understanding the link between internal states and decision-making in higher organisms, such as the integration of emotion and cognition in humans (Salzman and Fusi 2010).

\section{STATE-DEPENDENT CONTROL OF SOCIAL BEHAVIORS IN DROSOPHILA}

\section{A Neuron and a Neuropeptide That Control Aggressive Arousal}

Evidence from many systems suggests that neuromodulators, such as biogenic amines or neuropeptides, are important regulators of internal states and behavior (Insel and Young 2000; Nassel and Winther 2010; Bargmann 2012; Marder 2012; Taghert and Nitabach 2012). As a first step toward understanding the neural coding of a state of aggressiveness, we carried out a screen for neuropeptide-secreting neurons that control agonistic behavior in Drosophila (Asahina et al. 2014). This screen identified a small cluster (three to five cells) of male-specific, fruitless (FruM)-expressing neurons (Fig. 2A-C) that contain the neuropeptide Drosophila tachykinin (DTK, Fig. 2A, inset) and that profoundly influence levels of aggressiveness. Thermogenetic activation of these neurons increased aggression (Fig. 2D), whereas inhibition of these neurons strongly reduced fighting (Fig. 2E; Asahina et al. 2014). Overexpression of the DTK peptide in DTKexpressing neurons potentiated the aggression-promoting effect of activating these cells, whereas deletions in the DTK gene reduced it (Fig. 2F). Importantly, activation of these neurons had no effect on courtship or mating behavior. Together, these data identified a cell type and a gene that play a major role in controlling inter-male aggression in flies. Interestingly, homologs of DTK such as Substance $\mathrm{P}$ have been implicated in aggression in mammals 

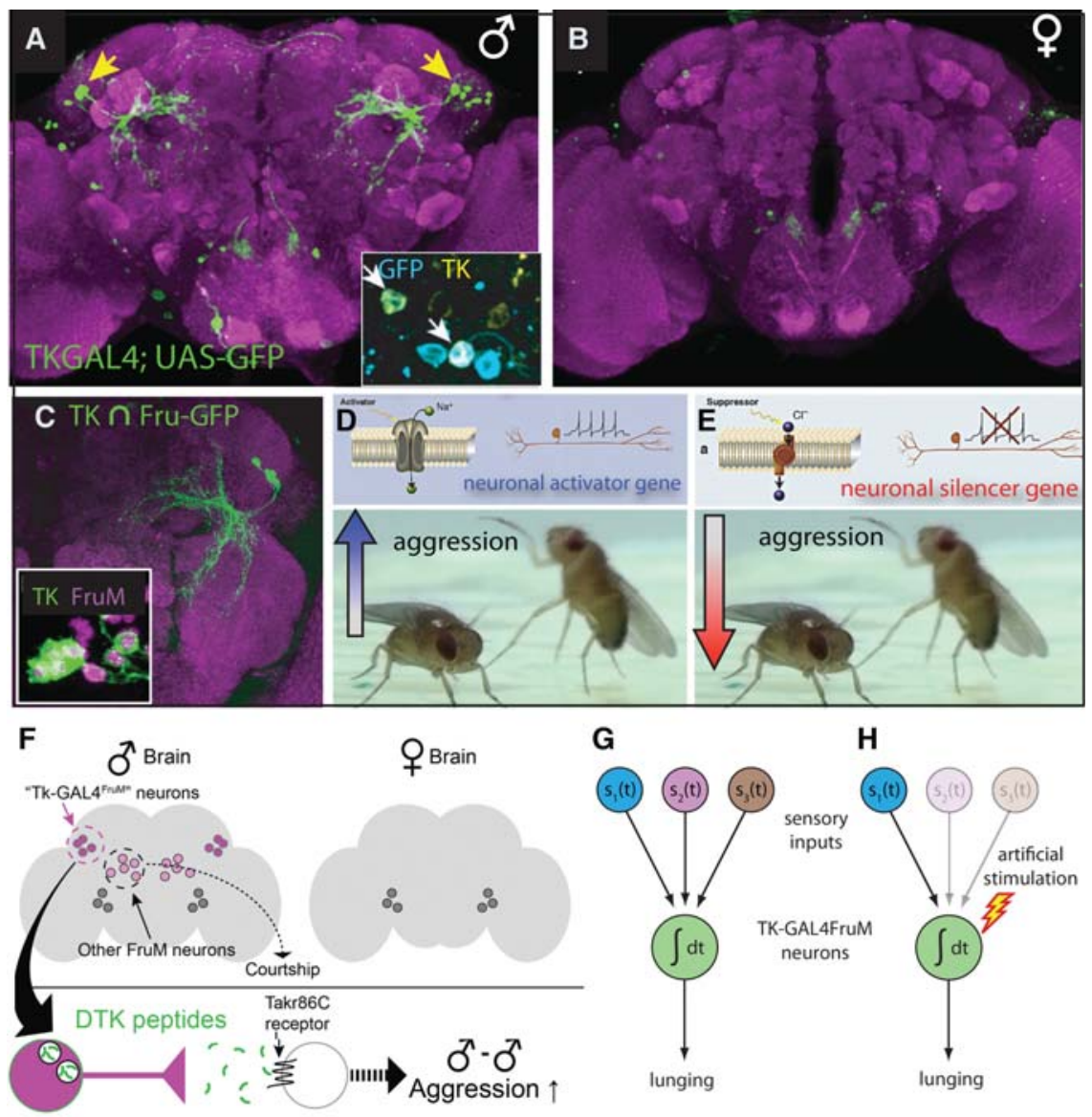

Figure 2. $(A, B)$ Identification of a population of aggression-promoting, sexually dimorphic neurons in male flies that express the neuropeptide Drosophila tachykinin (DTK) $(A$, inset). Yellow arrowheads $(A)$ indicate cell bodies. $(C)$ TK-GAL4 neurons express the male-specific sex-determination factor $\mathrm{Fru}^{\mathrm{M}}$ (inset). $(D, E)$ Activation of TK-GAL4 ${ }^{\mathrm{FruM}}$ neurons increases aggression $(D)$, whereas inhibition of these neurons decreases aggression $(E)$. $(F)$ The aggression-promoting function of TK-GAL4 ${ }^{\text {FruM }}$ neurons is enhanced by release of DTK peptides. $(G)$ TK-GAL4 ${ }^{\text {FruM }}$ neurons are proposed to integrate the effects of multiple classes of sensory stimuli over time $\left(\mathrm{s}_{1}(t), \mathrm{s}_{2}(t)\right.$, etc.). $(H)$ Artificial enhancement of TK-GAL4 ${ }^{\text {FruM }}$ neuronal activity can bypass the requirement for some of these sensory stimuli. ( $D, E$, Cartoons modified from Borst 2009, with permission from Elsevier; $F$, reproduced from Asahina et al. 2014.)

(including humans), by genetic and pharmacological studies (Shaikh et al. 1993; Katsouni et al. 2009; Coccaro et al. 2012).

Do DTK ${ }^{\text {FruM }}$ neurons simply direct a motor program of aggression or do they regulate an internal aggression-promoting state, such as motivation or arousal? Arousal often involves an increased sensitivity to sensory cues, such that the threshold for release of a stimulus-driven behavior is reduced (Van Swinderen and Andretic 2003, 2011; Devidze et al. 2006). Interestingly, artificial activation of DTK $^{\text {FruM }}$ neurons could evoke aggression even in the absence of sensory cues that are normally required for aggression, such as male-specific pheromones (Fig. 2G,H; de la Paz Fernandez et al. 2010; Wang and Anderson 2010; Wang et al. 2011). In some cases, activation of DTK $^{\text {FruM }}$ neurons supplemented with excess DTK peptide could even promote attack toward a moving fly-sized inanimate object (Asahina et al. 2014). These data suggest that DTK ${ }^{\mathrm{FruM}}$ neurons promote a state of arousal or motivation that is apparently aggression-specific. Our previous work has provided evidence of other behavior- specific forms of arousal in Drosophila (Lebestky et al. 2009).

We have recently suggested that emotions are internal states that are characterized by certain general properties, or emotion primitives, common to different emotions in a single species and that apply to emotions across species (Anderson and Adolphs 2014). These properties include persistence, scalability, valence, stimulus degeneracy, and generalization (trans-situationality). Neuropeptides have properties that could contribute to encoding some of these emotion state features (Flavell et al. 2013; for review, see Insel and Young 2000; Berridge 2004; Nassel and Winther 2010; Bargmann 2012). For example, the concentration of DTK could encode the scalability (intensity) of an aggressive state, whereas slowly decaying levels of the peptide, determined by its rate of degradation, could underlie a persistent state of aggressiveness. The relationship between $D T K$ gene dosage and the aggression-promoting activity of TK ${ }^{\mathrm{FruM}}$ neuron activation suggests that levels of DTK might control the intensity of aggression, but whether these neurons can induce a persistent state of aggres- 
siveness is not yet clear. Work from Kravitz and others indicates that biogenic amines, such as octopamine, dopamine, and serotonin, also influence levels of aggressiveness in Drosophila (Dierick and Greenspan 2007; Zhou et al. 2008; Mundiyanapurath et al. 2009; Alekseyenko et al. 2010, 2013; Certel et al. 2010; Andrews et al. 2014), as well as in other arthropod species (Stevenson et al. 2005; for review, see Kravitz and Huber 2003), and likely contribute to aggressive state control as well.

\section{Neurons That Control Persistent Social Behavior States in Drosophila}

The ability to identify neurons that control persistent behavioral states requires a means of activating such neurons in freely moving animals, with millisecond time resolution. This requirement is, of course, afforded by optogenetics; however, the use of optogenetics in Drosophila has been limited by the inability of blue light to penetrate the flies' cuticle. Recently, this obstacle has been overcome by the development and application of red-shifted opsins such as ReaChR (Fig. 3A) and Chrimson (Lin et al. 2013; Inagaki et al. 2014; Klapoetke et al. 2014).

In a proof-of-principle application of this technology, we performed optogenetic stimulation of different populations of interneurons that control wing extension, which mediates male courtship song (Kohatsu et al. 2011; von Philipsborn et al. 2011); (Fig. 3B,C; for review, see Yamamoto et al. 2014). Strikingly, activation of P1 interneurons in single male flies evoked probabilistic and persistent wing extension that lasted for many minutes following stimulus termination (Fig. 3D; Inagaki et al. 2014). In contrast, activation of a descending interneuron, pIP10 (Fig. 3B; von Philipsborn et al. 2011), evoked wing extension in a deterministic manner time-locked to the onset and offset of photostimulation (Fig. 3E). Similar observations were made independently using IR laserbased transient thermogenetic activation of P1 and pIP10 (Bath et al. 2014). Interestingly, transient activation of $\mathrm{P} 1$ neurons in pairs of male flies evoked persistent aggression (Fig. 3F; E Hoopfer and DJ Anderson, unpubl.). These results indicate that $\mathrm{P} 1$ neurons can regulate aggression as well as courtship (Fig. 3G), although whether their influence on aggression is direct or indirect remains to be determined.

The persistent effect of $\mathrm{P} 1$ neuron activation on courtship raised the question of whether these neurons might be involved in internal states of arousal or motivation associated with such reproductive behaviors. Social isolation is known to increase both courtship and aggression in flies (Wang et al. 2008; Liu et al. 2011), as well as in many other animal species (Koike et al. 2009; Toth et al. 2011). Strikingly, social isolation potentiated the effect of optogenetic activation of P1, but not of pIP10 neurons, to promote wing extension (Inagaki et al. 2014). Moreover, this effect was associated with an increased excitability of P1 neurons, as determined by combined optogenetic stimulation and calcium imaging experiments. These data suggest that P1 neurons could form

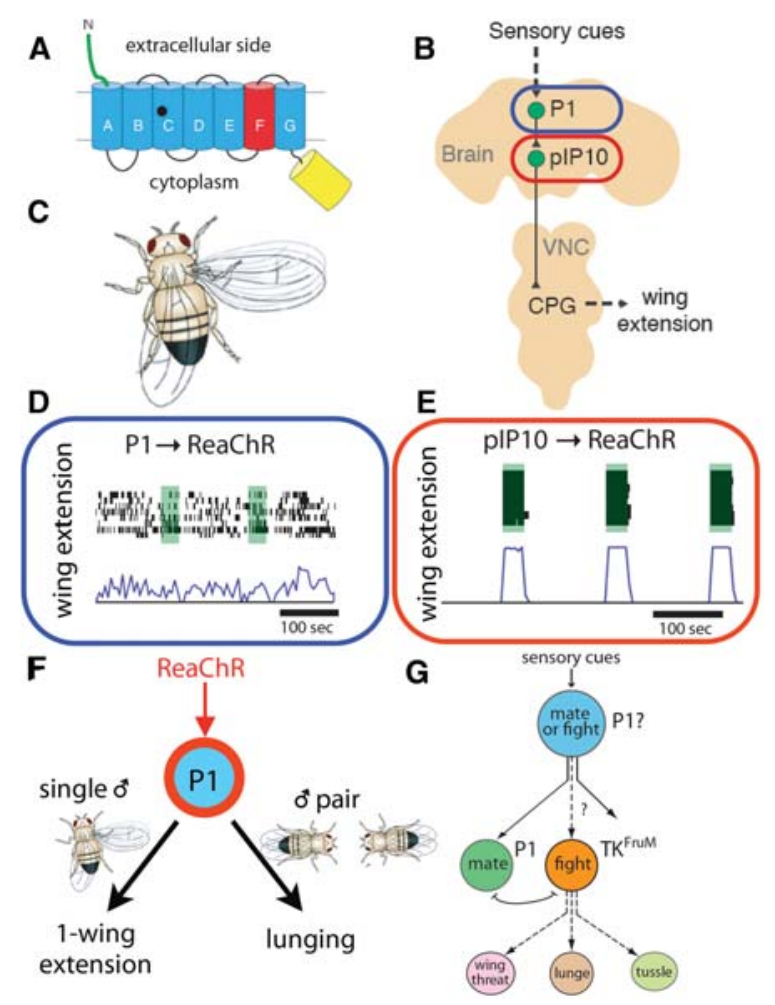

Figure 3. (A) Schematic illustrating the red-shifted opsin ReaChR (Lin et al. 2013; Inagaki et al. 2014). (B,D) Cartoon illustrating two classes of interneurons that control wing extension $(C)$ in male Drosophila. $(D, E)$ Optogenetic activation of P1 and pIP10 neurons evokes persistent and time-locked wing extension in single Drosophila males, respectively. $(F)$ Schematic illustrating dual effect of P1 activation by ReaChR to evoke courtship behavior (1-wing extension) in single males (left), and aggressive behavior in pairs of males (right) (E Hoopfer et al. in prep.) $(G)$ Schematic illustrating possible circuit relationship between P1 neurons and TK-GAL4 ${ }^{\text {FruM }}$ neurons. $(B-C$, Modified from von Philipsborn et al. 2011; $D, E$, modified from Inagaki et al. 2014.)

part of the neural substrate for an internal state change that reflects social experience and that affects multiple social behaviors (Wang et al. 2008; Liu et al. 2011). The persistent behavioral effects of P1 activation might then serve to perpetuate the influence of past environmental conditions on behavior.

\section{NEURAL CONTROL OF AGGRESSION IN MICE}

Classic experiments by Hess in the late 1920s demonstrated that electrical stimulation of the hypothalamus could elicit aggressive displays in cats (Hess 1928), such as the "affecktiven Abwehr-reaktion" ("affective defensive reaction"), in which the animal exhibited hissing, baring of teeth, and laid-back ears characteristic of a state of "rage" (Hess and Brügger 1943). This transformative experiment suggested that artificial stimulation of a specific brain region could evoke an emotion state and its associated behavioral expression. 
Hess's findings raised three major questions: (1) What neurons are sufficient to evoke aggression when artificially stimulated? (2) Are those same neurons required for normal aggressive behavior? (3) Are those neurons normally active during aggressive behavior? (Kruk 2014). Despite almost a century of follow-up research (for review, see Kruk 1991; Siegel et al. 1999; Siegel 2004; Adams 2006; Miczek et al. 2007; Nelson and Trainor 2007; Anderson 2012; Falkner and Lin 2014; Yang and Shah 2014), until recently, these questions have remained unanswered. ${ }^{7}$ They could potentially be addressed by bringing to bear powerful genetic tools for neural circuit manipulations available in mice. Surprisingly, however, in the $70 \mathrm{yr}$ since Hess's initial paper, there was no report of brain-stimulated aggression in mice, ${ }^{8}$ despite the fact that such manipulations are routine in other rodent species such as rats and hamsters (Kruk 2014).

\section{Identification of an Aggression Locus in the Mouse Hypothalamus}

To identify neurons activated during aggression, we carried out multi-electrode, single-unit recordings from the ventrolateral subdivision of the ventromedial hypothalamus (VMHvl), in freely behaving male mice (Lin et al. 2011). We chose VMHvl because it overlaps the so-called hypothalamic attack area (HAA) identified by microstimulation experiments in rats (Kruk et al. 1988; Hrabovszky et al. 2005) and because it is labeled strongly by c-fos following aggression (Newman 1999; Veening et al. 2005; Lin et al. 2011). Extracellular recording in VMHvl revealed that it contains neurons with dynamic and heterogeneous responses during social encounters, with some units activated during male-male (Fig. 4A) or male-female (Fig. 4B) interactions, or both (Fig. 4C; Lin et al. 2011); a small number of units were active exclusively during attack or mounting (Fig. 4D). Thus, VMHvl contains a mixture of neurons active during different phases and different types of social encounters (Fig. 4E).

To investigate a causal role for $\mathrm{VMHvl}$ neurons in aggression, we optogenetically activated these cells, using channelrhodopsin-2 (ChR2), in an anatomically restricted (but not cell-type-specific) manner (Lin et al. 2011). Photostimulation elicited time-locked attack toward males, females, and inanimate objects, with a latency of a few seconds. Chemogenetic inhibition using an

\footnotetext{
${ }^{7}$ The main reasons for this are that (1) the electrical stimulation techniques used did not have sufficient resolution to distinguish relevant neurons from fibers-of-passage; (2) lesion experiments in relevant hypothalamic regions yielded conflicting results; and (3) methods for recording the activity of single units in freely moving animals were not available.

${ }^{8}$ We now know that this is because the experiment does not work Because the mouse brain is much smaller than the rat brain, electrical current delivered to sites containing attack neurons spreads to adjacent sites that promote defensive behaviors, which are dominant to social behaviors such as fighting and mating (at least when artificially stimulated). The advantage of optogenetic activation is that it allows restriction of activation to cell bodies, by combining focal injection of viruses with localized photostimulation.
}
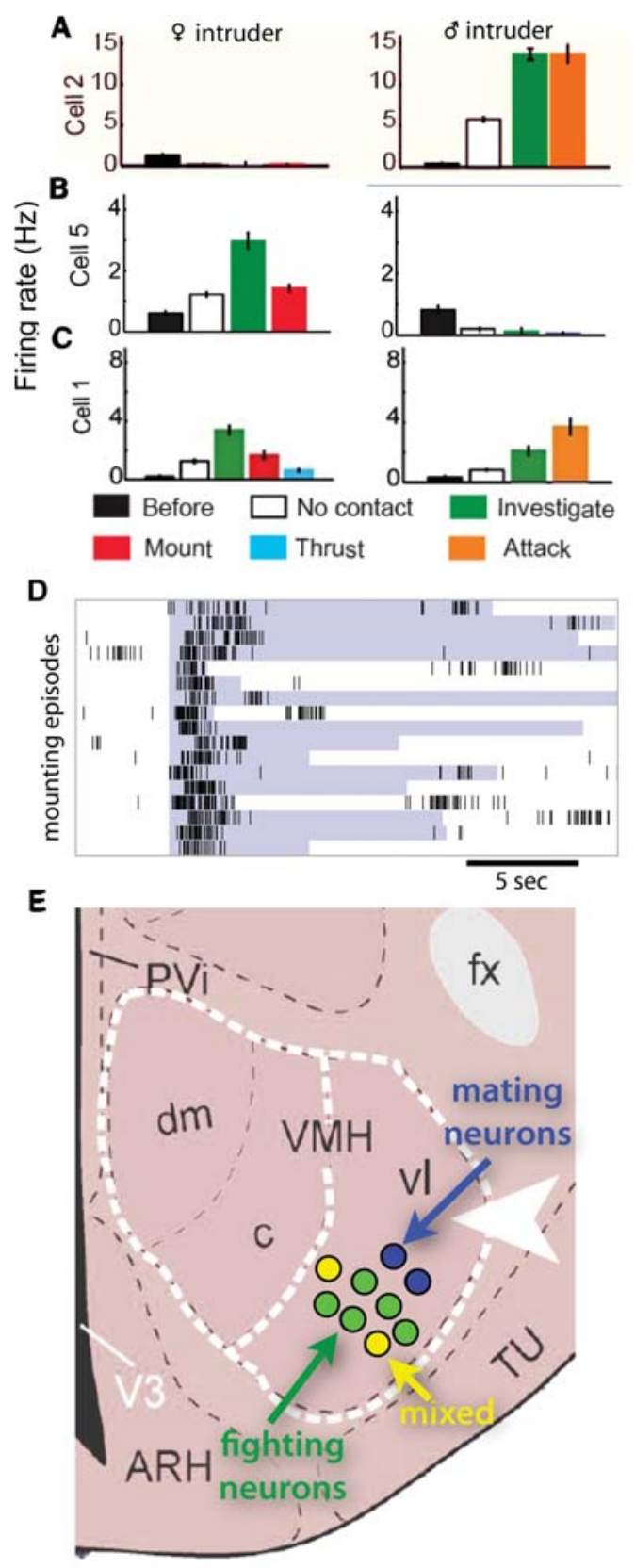

Figure 4. $(A-C)$ Average firing rates (in 5-sec bins) for three individual units recorded in the $\mathrm{VMHvl}$ of a male mouse during the indicated social behavior epochs (established by manual annotation of videos at $30 \mathrm{~Hz}$ ) (Lin et al. 2011). (D) Raster plot of an individual unit in VMHvl during mounting. Each row illustrates a separate trial. Shading indicates periods where mounting occurred. $(E)$ Schematic illustrating mixed population of neurons in VMHvl that are responsive during male social behavior. (Modified from Anderson 2012.)

ivermectin-gated chloride channel (Slimko et al. 2002; Lerchner et al. 2007) reversibly reduced agonistic behavior (Lin et al. 2011). However, the temporal resolution of this method was insufficient to determine whether these neurons were required during attack per se. Surprisingly, 
neither manipulation caused any change in male-female mating behavior, despite the presence of female-responsive units in VMHvl (Lin et al. 2011).

\section{Genetic Identification of Hypothalamic Aggression Neurons}

The foregoing experiments indicated that VMHvl contains neurons involved in attack, but they did not identify these cells. They also did not account for the function of
VMHvl neurons activated by females; in principle, such neurons could promote mating, inhibit aggression, or both (Anderson 2012). To address these issues, we sought to identify molecular markers for these neurons. We found that VMHvl contains a subset $(\sim 40 \%)$ of neurons that express the type 1 estrogen receptor (Esr1; Fig. 5A), $\sim 30 \%$ of which are activated during attack as determined by double-labeling for c-fos (Fig. 5H; Lee et al. 2014). To manipulate the function of these neurons, we generated gene-targeted mice expressing Cre recombinase in $E s r 1^{+}$
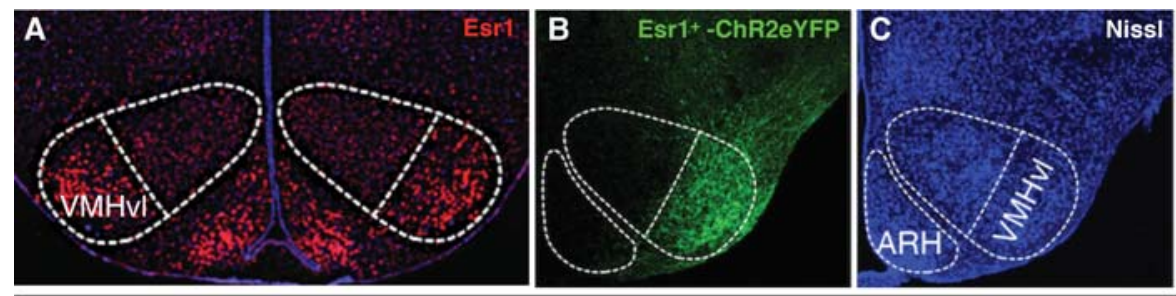

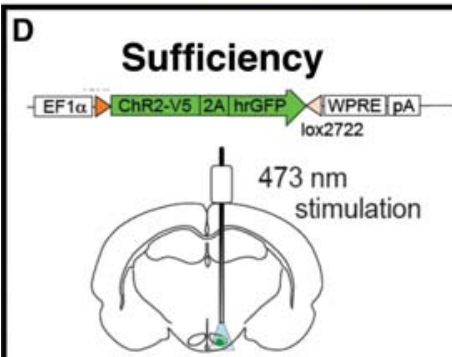

$\mathrm{Esr1}^{+} \mathrm{ChR2}^{+}$

\section{$\mathbf{E}$}
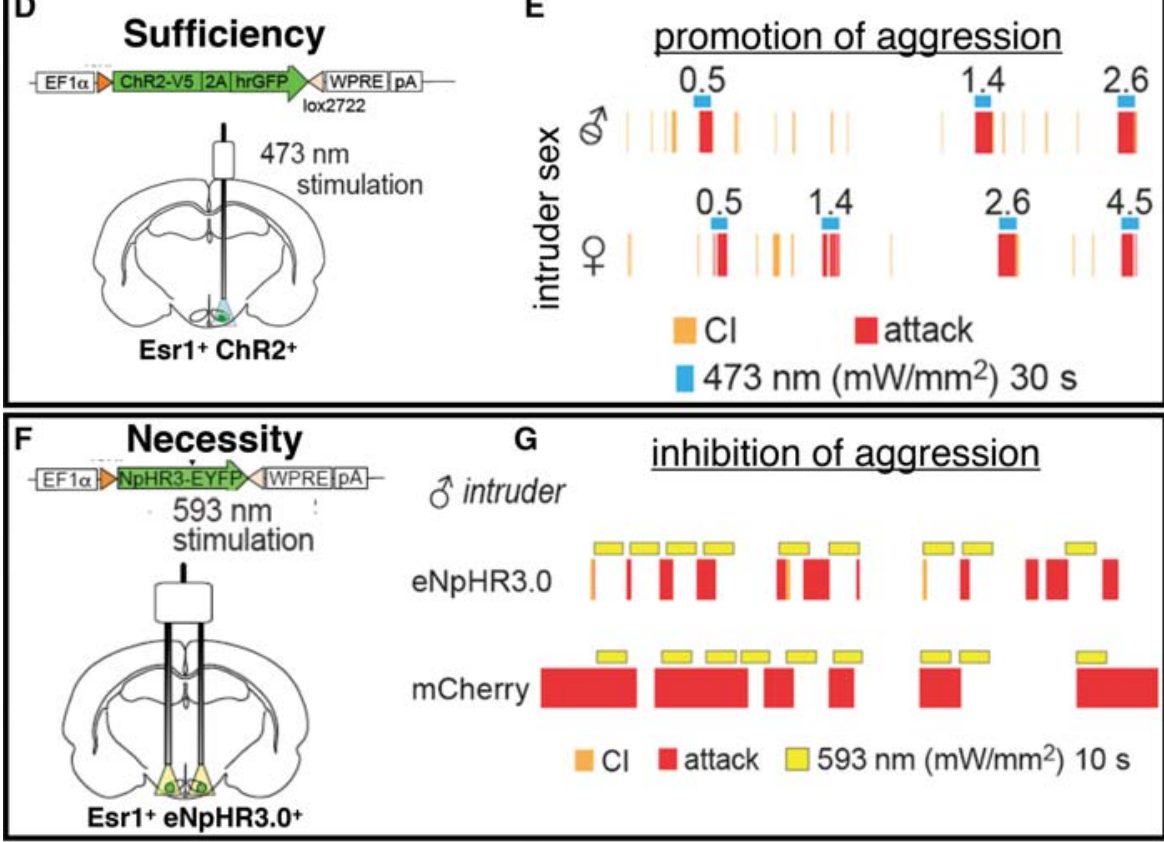

\section{Activity}
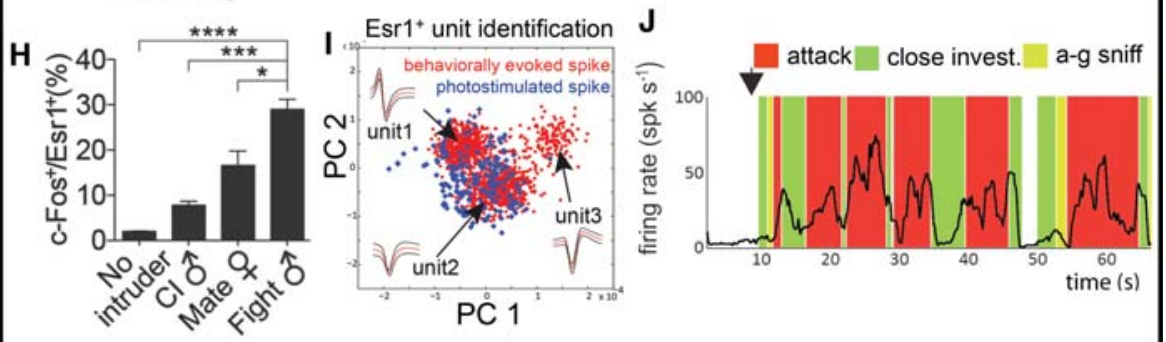

Figure 5. (A) Expression of Esr1 in VMHvl. (B) Expression of eYFP in Esr1 ${ }^{+}$neurons in an Esr 1-Cre mouse injected in VMHvl with a Cre-dependent AAV encoding ChR2-eYFP. $(C)$ Nissl staining of the same section as in $B$. ARH, arcuate nucleus. $(D, E)$ Optogenetic activation of VMHvl Esr ${ }^{+}$neurons promotes attack. $(F, G)$ Optogenetic inhibition of VMHvl Esr $1^{+}$neurons inhibits attack compared to control (mCherry). $(H)$ Induction of c-FOS in Esr1 ${ }^{+}$neurons following different social interactions. CI, close investigation. (From Lee et al. 2014.) $(I, J)$ An Esr1 ${ }^{+}$neuron expressing ChR2 in VMHvl, identified by optogenetic phototagging using a chronically implanted optrode array, is active during attacks $(J)$. $(I)$ Plot illustrating overlap in principal component space between waveforms of optogenetically (blue) and behaviorally (red) evoked spikes from Esr1 ${ }^{+}$neurons in VMHvl. PC, principal component. 
neurons, allowing cell-type-specific expression of optogenetic effectors in VMHvl (Fig. 5B,C).

Optogenetic activation of $\mathrm{Esrl}^{+}$neurons in $\mathrm{VMHvl}$ indicated that they were sufficient to promote attack (Fig. 5D,E), whereas activation of Esr1 ${ }^{-}$neurons was not (Lee et al. 2014). Time-resolved optogenetic inhibition of $\mathrm{Esrl}^{+}$neurons interrupted ongoing attack (Fig. $5 \mathrm{~F}, \mathrm{G})$, indicating that their activity is required during this consummatory phase of an aggressive encounter, confirming and extending earlier loss-of-function studies (Lin et al. 2011; Sano et al. 2013; Yang et al. 2013). ${ }^{9}$ Finally, preliminary experiments using optogenetic phototagging (Lima et al. 2009) to identify Esr ${ }^{+}$neurons in multi-electrode recordings indicate that these cells exhibit increased spiking rates during attack (Fig. 5I-J; R Remedios and DJ Anderson, unpubl.). Together, these data indicate that $\mathrm{Esrl}^{+}$neurons in VMHvl fulfill the three major criteria necessary to identify them as attack neurons (Kruk 2014): they are sufficient to elicit attack when artificially stimulated; they are necessary for naturally occurring attack; and they are active during normal aggressive behavior.

\section{Scalable Control of Social Behavior by VMHvl Esr $1^{+}$Neurons}

Systematic variation of optogenetic stimulation parameters revealed, unexpectedly, that although high levels of stimulation evoked attack, lower levels ${ }^{10}$ evoked nonagonistic social behaviors, including sniffing or close investigation $(\mathrm{CI})$ and attempted mounting (Figs. 6A, 7A; Lee et al. 2014). Mounting was evoked toward normal and castrated males as well as females, with equal efficacy. Remarkably, in some cases, the social behaviors evoked within a single stimulation session could be shifted, simply by increasing the light intensity used for photostimulation, from mounting to attack (Fig. 6A,B). The threshold for mounting and CI was similar, and approximately six- to sevenfold lower than that required to evoke attack (Fig. 6C).

Together, these data suggest that optogenetic activation of VMHvl Esr1 ${ }^{+}$neurons evokes different social behaviors in a scalable manner (Lee et al. 2014): Low-intensity stimulation evokes appetitive and sexual behavior-social investigation and mounting-whereas higher intensities evoke attack (Figs. 6B, 7A). Interestingly, we have

\footnotetext{
${ }^{9}$ Previous studies indicated that killing progesterone receptor (PR)expressing neurons in VMHvl (which overlap Esr1 ${ }^{+}$neurons by $90 \%$ ) partially reduced aggression (Yang et al. 2013), as did RNAi-mediated knockdown of Esr1 in VMHvl (Sano et al. 2013). However, because of the long delay between the manipulation and behavioral testing $(2-3$ wk), these studies could not distinguish a permissive requirement for VMHvl, e.g., in the detection of chemosensory cues essential for male-male recognition, from a requirement during attack per se.

10"Lower levels" were achieved by (1) injecting fewer ChR2-expressing viral particles; (2) incubating the animals for a shorter period of time following viral injection (which results in lower levels of ChR2 expression); (3) reducing the light intensity used in photostimulation; and (4) reducing the frequency of photostimulation (although reduced frequency was less effective than reduced light intensity). These data suggest that it is the number of activated cells, and the level of activity per cell, which is responsible for the observed behavioral differences.
}

recently observed similar results following optogenetic stimulation of GABAergic neurons in the medial amygdala (Hong et al. 2014), a structure that projects indirectly to VMHvl (Canteras et al. 1992, 1995; Swanson 2000). We have also observed scalable control of different defensive behaviors - avoidance, freezing, and flight - following stimulation of a different subpopulation of $\mathrm{VMH}$ neurons located in its dorsomedial subdivision (Kunwar et al. 2015). These observations suggest that scalable control may be a general feature of hypothalamic cell populations controlling innate motivated behaviors. Although such stimulation intensity-dependent changes in evoked behavior have been previously observed using electrical methods (von Holst and von Saint Paul 1960, 1962), the use of optogenetic tools to restrict activation to genetically identified neuronal cell bodies rules out the possibility that such behavioral switches simply reflect current spread to neighboring brain regions, a possibility that could not be excluded in early studies.

\section{Role of Esr1 ${ }^{+}$Neurons in Male-Male Social Interactions}

Several lines of evidence suggest that the relationship between increasing optogenetic stimulation of VMHvl Esr $1^{+}$neurons, and the change in evoked behavior from investigation to attack, reflects a control mechanism that operates during naturally occurring male-male social encounters. First, the fraction of Esr1 ${ }^{+}$neurons that are activated $\left(\mathrm{c}-\mathrm{fos}^{+}\right)$following attack is approximately fiveto sixfold higher than after close investigation without attack (Fig. 5H; Lee et al. 2014). Second, electrophysiological recordings in $\mathrm{VMHvl}$ indicate that the average spiking rate ramps up quickly during the progression from CI to attack and that investigation is more likely to be followed by attack when the spiking rate is high (Fig. 6E; Lin et al. 2011; Falkner et al. 2014). Finally, and most importantly, time-resolved optogenetic inhibition delivered during the initial phase of a social encounter interrupts close investigation (Fig. 6D; Lee et al. 2014). Thus, inhibition of $\mathrm{Esrl}^{+}$neurons can interrupt either close investigation or ongoing attack (Fig. 7B), depending on when photostimulation is delivered. Together, these data are consistent with the idea that the behavioral progression during a male-male aggressive encounter is controlled in a scalable, threshold-dependent manner, according to the level of activity among VMHvl Esr1 ${ }^{+}$ neurons (Fig. 6B).

\section{Role of Esr1 ${ }^{+}$Neurons in Male-Female Social Interactions}

A role for VMHvl in male sexual behavior is unexpected, as this function has traditionally been assigned to the MPO (Simerly 2002; Yang and Shah 2014). Optogenetic stimulation experiments should be interpreted with caution, because artificial patterns of activation could produce abnormal behaviors. Male mounting has been suggested to be a "default" social behavior (Stowers 
A

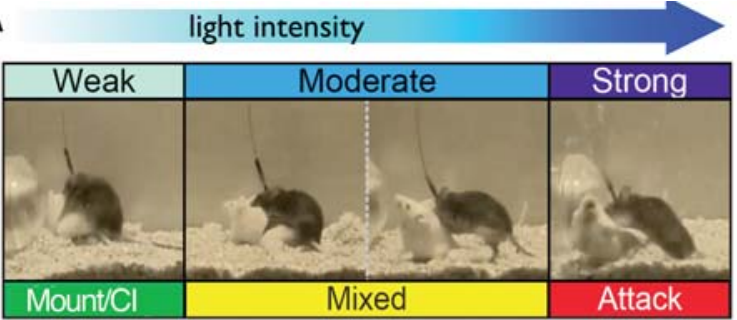

B

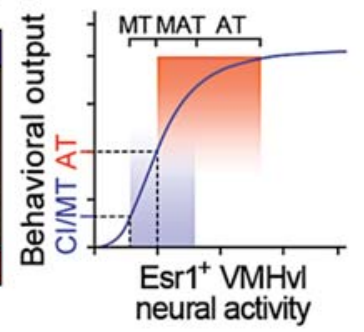

C

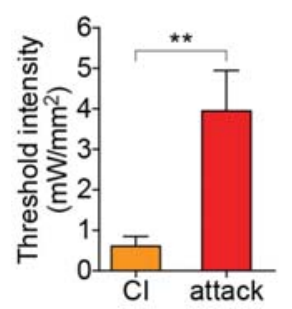

D
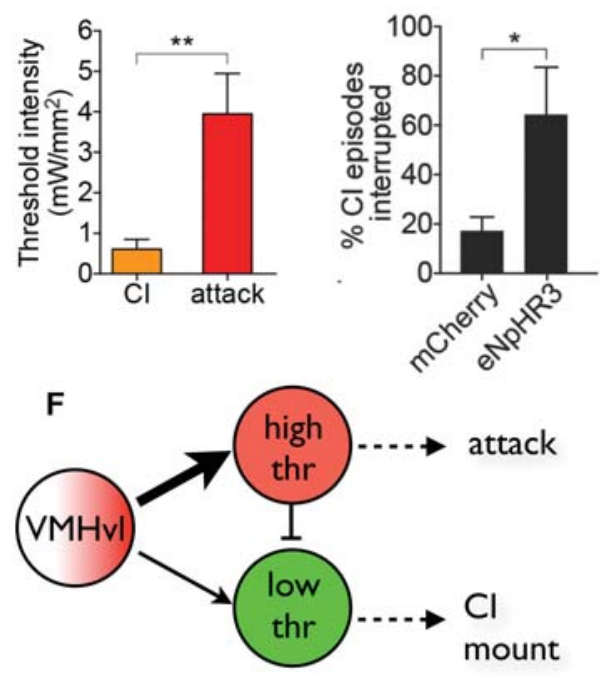

E

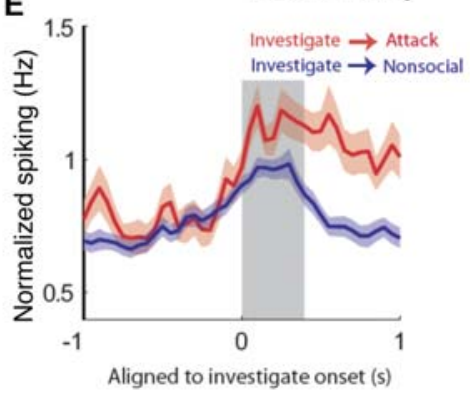

G

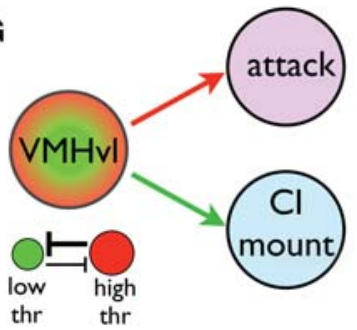

Figure 6. $(A, B)$ Social behavior evoked by optogenetic stimulation of VMHvl Esr1 ${ }^{+}$neurons switches from close investigation (CI) and mounting at low light intensity, to attack at high intensity. (C) Threshold intensities required to elicit CI versus attack. (D) Interruption of naturally occurring close investigative behavior (CI) by optogenetic inhibition of Esr $1^{+}$neurons delivered during sniffing (vs. mCherry control). (E) Average spiking activity during the last $400 \mathrm{msec}$ of sniffing preceding attack (red) or nonsocial behavior (blue). A higher level of spiking during the sniffing period predicts subsequent attack. $(F, G)$ Alternative models to explain intensity dependence of optogenetically evoked behaviors from Esr $1^{+}$neurons. $(F)$ The level of activity among a common population of $\mathrm{VMHvl} \mathrm{Esr1}{ }^{+}$neurons activates behavior-specific downstream centers with low versus thresholds for activation. Thickness of arrows indicates relative level of activity in VMHvl output required to produce behavior. $(G)$ Distinct and mutually inhibitory subsets of VMHvl Esr1 ${ }^{+}$neurons controlling mounting (green) or attack (red) have low versus high thresholds for activation, respectively; output from the dominant population (red vs. green arrows) determines behavioral outcome. ( $A-D$, Modified from Lee et al. 2014; $E$, modified from Falkner et al. 2014, with permission from the Society for Neuroscience.)

et al. 2002); thus, low-intensity stimulation of VMHvl Esr $^{+}$neurons could lead to mounting by default. Nevertheless, genetic ablation of progesterone receptor (PR)expressing VMHvl neurons (Yang et al. 2013) (which highly overlap Esr1 ${ }^{+}$neurons) or knockdown of Esr1 mRNA in VMHvl (Sano et al. 2013) both significantly reduced male mounting toward females. These data are consistent with the idea that VMHvl does play a role in normal male sexual behavior. However, acute optogenetic inactivation of $\mathrm{Esr}^{+}$neurons did not interrupt normal male-female mounting in media res (Fig. 7B; Lee et al. 2014). ${ }^{11}$ Interestingly, the average spiking rate in VMHvl

\footnotetext{
${ }^{11}$ Negative results must also be interpreted with caution, however, especially in the case of loss-of-function manipulations. The inability to arrest mounting by optogenetic inhibition of Esr $1^{+}$neurons could reflect a redundant role for other structures (e.g., MPO), or incomplete inhibition of activity. Genetic ablation (Yang et al. 2013), although it lacks temporal resolution, completely eliminates the activity of a given population of neurons.
}

decreased dramatically as male-female sexual encounters progressed from investigation and mounting to intromission and ejaculation (Lin et al. 2011). It is possible, therefore, that the role of Esr $1^{+}$neurons in male sexual behavior is limited to the detection of chemosensory cues required for recognition of females, rather than for male copulatory behavior per se.

Our finding that mounting was evoked by weaker optogenetic stimulation of VMHvl Esr1 ${ }^{+}$neurons than was required to trigger attack was also unexpected. However, it is consistent with the observation that fewer of these neurons are $\mathrm{c}-\mathrm{fos}^{+}$following an encounter with a female, than with a male (Lin et al. 2011; Lee et al. 2014; Fig. $5 \mathrm{H})$. Does this mean that the decision of whether to fight or mate is controlled simply by the level of population activity among VMHvl Esr $1^{+}$neurons? It is possible that a low level of output from VMHvl activates low-threshold neurons in a downstream target structure that mediates CI or mounting, whereas a higher level of output 
A

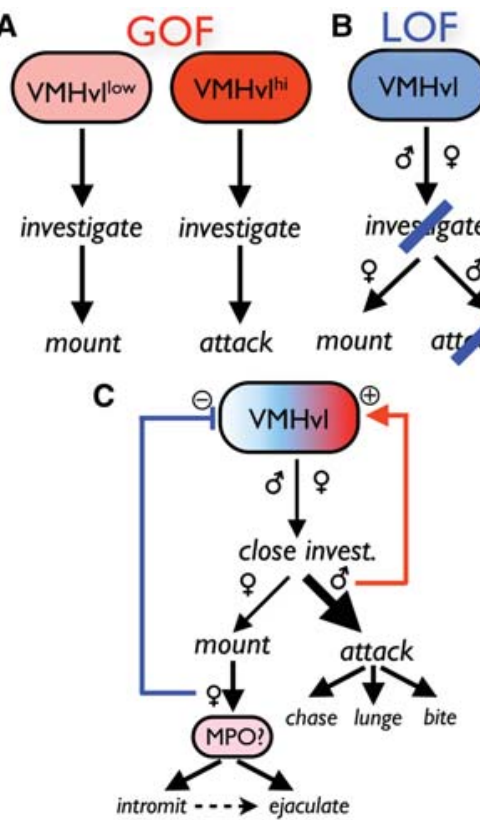

Figure 7. $(A, B)$ Summary of gain-of-function $(A, \mathrm{GOF})$ and loss-of-function $(B, \mathrm{LOF})$ phenotypes obtained by optogenetic manipulation of VMHvl Esr1 ${ }^{+}$neurons. Blue bars in $B$ indicate behaviors interrupted by optogenetic inhibition. $(C)$ Schematic illustrating a hypothetical view of the function of Esr $1^{+}$neurons in VMHvl during a normal male-male or male-female social encounter. Thickness of arrows denotes relative level of output (spiking rate and/or number of active output neurons required to produce behavior). Blue versus red shading in VMHvl indicates gradual decrease (blue) or increase (red) in average spiking rate during an evolving male-female (blue) or male-male (red) social encounter. Colored arrows indicate behavioral feedback. See text for details.

activates high-threshold neurons in a different target that mediates attack; the latter could then inhibit the former (Fig. 6F). Alternatively, the intensity-dependent effects of optogenetic stimulation might reflect the existence of different, sex-specific subpopulations of Esr $1^{+}$neurons, with female-specific neurons activated at a lower threshold than male-specific neurons (Lee et al. 2014). ${ }^{12}$ If so, then asymmetric and reciprocal inhibition between these Esr $^{+}{ }^{+}$neuronal subpopulations could determine whether output from these neurons promotes mating or fighting (Fig. 6G).

Whether the optogenetic results (Fig. 7A) reflect intensity coding or cellular heterogeneity, our electrophysiological recordings suggest a dynamic and time-evolving role for VMHvl neurons during a natural social encounter (Fig. 7C). Most of the neurons activated during both male-female and male-male encounters are most active at the initial phases of a social encounter (Lin et al. 2011). Perhaps these neurons promote approach and close (anogenital) investigation of a conspecific to identify intruder

\footnotetext{
${ }^{12}$ Note, however, that optogenetic stimulation of Esr $1^{+}$neurons in VMHvl slices, together with calcium imaging using GCaMP6s, did not induce a different pattern of neuronal activity at low versus high stimulation intensities, but rather simply increased the number of active neurons and the average level of activity per cell (Lee et al. 2014).
}

gender, which requires detection of short-range, sex-specific pheromonal cues (Fig. 7C, "close invest"; Brennan and Zufall 2006; Dulac and Wagner 2006). The recognition of a male would promote further social investigation, ramping up the activity of VMHvl neurons in a positivefeedback manner, until the threshold for attack was reached (Fig. 7C, red arrow). The recognition of a female would promote initial attempts at mounting, with further interactions driving a reduction of activity in $\mathrm{VMHvl}$ and initiating the engagement of other structures, such as the MPO, that may promote the consummatory phase of a sexual encounter (Fig. 7C, blue arrow). This speculative scenario incorporates both sex-specific subpopulations and dynamic changes in population activity among VMHvl Esr $1^{+}$neurons during social encounters.

\section{SOCIAL BEHAVIOR CONTROL CENTERS: RHEOSTATS OR SWITCHES?}

The foregoing data indicate that artificial activation of VMHvl (and MeApd) neurons at different intensities can evoke different types of social behavior at different thresholds (Hong et al. 2014; Lee et al. 2014) and that the average spiking rate among VMHvl neurons increases as animals progress from investigative to attack behavior (Lin et al. 2011; Falkner et al. 2014). Together, these findings raise the intriguing possibility that VMHvl encodes the intensity of an escalating state of arousal, motivation, or drive, in a graded manner according to its level of activity (Fig. 8A, "social behavior control center"). This increasing level of activity may reflect changes in sensory input as a social encounter evolves over time (e.g., via an increase in the concentration of olfactory cues during close investigation) (Fig. 8A, "sensory inputs"). Such escalation could, in turn, be used to control transitions between different behaviors by activating lower-level command centers controlling these behaviors (Fig. 8A; $\mathrm{B}_{1}, \mathrm{~B}_{2}$, etc.) at different thresholds, perhaps according to the level of tonic inhibition imposed on such centers (Fig. 8A, "action selection"). Such a model is analogous to the size principle proposed by Henneman to explain the progressive recruitment of larger motor units during muscle engagement (Henneman 1985). In this way, VMHvl could both encode the intensity of an internal state and couple the intensity of that state to behavioral decisions. Such a model integrates the Lorenzian view of behavioral control by drive state intensity (Fig. 1B) with the Tinbergian view of hierarchical control of behavioral decision-making (Fig. 1C).

Alternatively, VMHvl could act simply as a permissive switch, or gate, for social behavior, whereas action selection would be controlled by sensory inputs that act directly on the lower-level command centers (Fig. 8B). In this scenario, the level of motivation or arousal would have to be encoded elsewhere in the brain and might be a consequence, rather than a cause, of escalating behavior. The essential difference between these models is that in one case, the control center simply determines whether or not aggression or mating will occur (Fig. 8B), whereas in 
A
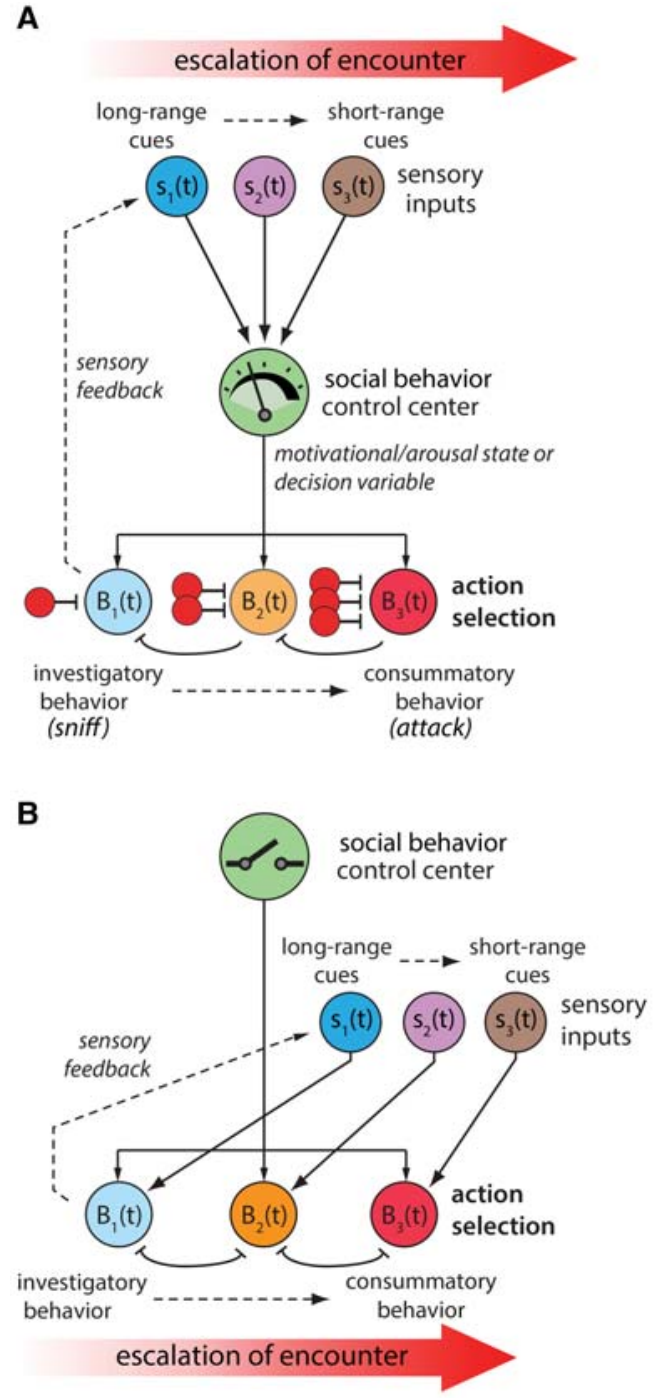

Figure 8. Alternative models for the control of action selection during an escalating social encounter. $(A)$ Neurons in a social behavior control center (green) function like a rheostat, which encodes the intensity of an escalating internal state (arousal, motivation, or drive) according to the integrated sensory input converging on this center. Common outputs from this center project to lower-level command centers controlling distinct behavioral actions occurring at different times $\left(\mathrm{B}_{1}(t), \mathrm{B}_{2}(t)\right.$, etc.); each command center receives the same amount of input from the higherlevel center. Command centers controlling investigatory (appetitive) to consummatory actions are held under progressively higher levels of tonic inhibition (red circles). Therefore, release from this inhibition occurs with progressively stronger output from the higher-level center, as the intensity of the internal state associated with the social encounter escalates. $(B)$ Alternative model in which the social behavioral control center functions simply as a switch or gate to allow agonistic behavior to occur, and different behavioral actions are controlled by the direct influences of changing sensory cues on lower-level command centers during an evolving social encounter. Models that combine features of $A, B$ are not illustrated but also possible.

the other case, it also controls the type of lower-level behavioral action that is selected (Fig. 8A). Distinguishing between these alternatives will require new methods for imaging neural population activity in freely behaving animals (Ghosh et al. 2011; Ziv et al. 2013; Jennings et al. 2015), more specific tools for identifying and functionally manipulating neuronal subtypes and their connectivity (Zeng and Madisen 2012; Oh et al. 2014), as well as the application of modeling and theory. The combination of such approaches should yield new mechanistic insights into the neural control of animal behavior and may shed light on the interaction between emotion states and decision-making in humans.

\section{ACKNOWLEDGMENTS}

We thank members of the Anderson laboratory, past and present, for their contributions to the data and ideas discussed in this article, including Todd Anthony, Vivian Chiu, Brian Duistermars, Tyler Gibson, Weizhe Hong, Dong-Wook Kim, Prabhat Kunwar, Kiichi Watanabe, Allan Wong, and Moriel Zelikowsky. A long-term collaboration with Prof. Pietro Perona, and his students Piotr Dollar, Carlos Gonzalez, and Eyrún Eyolfsdottir, has been essential in developing automated methods for behavioral analysis used in this work. We also acknowledge Dr. Hongkui Zeng and her colleagues at the Allen Institute for Brain Sciences for their ongoing collaborative contributions. We thank Gina Mancuso for administrative assistance and Celine Chiu for laboratory management. Portions of this work were supported by grants from the Ellison Medical Foundation, the Gordon and Betty Moore Foundation, the Simons Foundation, the Paul G. Allen Family Foundation, and National Institutes of Health grants MH070053, MH085082, and DA031389. D.J.A. is an Investigator of the Howard Hughes Medical Institute.

\section{REFERENCES}

Adams DB. 2006. Brain mechanisms of aggressive behavior: An updated review. Neurosci Biobehav Rev 30: 304-318.

Alekseyenko OV, Lee C, Kravitz EA. 2010. Targeted manipulation of serotonergic neurotransmission affects the escalation of aggression in adult male Drosophila melanogaster. PLoS One 5: e10806.

Alekseyenko OV, Chan Y-B, Li R, Kravitz EA. 2013. Single dopaminergic neurons that modulate aggression in Drosophila. Proc Natl Acad Sci 110: 6151-6156.

Anderson DJ. 2012. Optogenetics, sex, and violence in the brain: Implications for psychiatry. Biol Psychiatry 71: 1081-1089.

Anderson DJ, Adolphs R. 2014. A framework for studying emotions across species. Cell 157: 187-200.

Andrews JC, Fernández MP, Yu Q, Leary GP, Leung AK, Kavanaugh MP, Kravitz EA, Certel SJ. 2014. Octopamine neuromodulation regulates Gr32a-linked aggression and courtship pathways in Drosophila males. PLoS Genet 10: e1004356.

Asahina K, Watanabe K, Duistermars BJ, Hoopfer E, González CR, Eyjólfsdóttir EA, Perona P, Anderson DJ. 2014. Tachykinin-expressing neurons control male-specific aggressive arousal in Drosophila. Cell 156: 221-235.

Bargmann CI. 2012. Beyond the connectome: How neuromodulators shape neural circuits. Bioessays 34: 458-465.

Bath DE, Stowers JR, Hormann D, Poehlmann A, Dickson BJ, Straw AD. 2014. FlyMAD: Rapid thermogenetic control of neuronal activity in freely walking Drosophila. Nat Methods 11: $756-762$. 
Berridge KC. 2004. Motivation concepts in behavioral neuroscience. Physiol Behav 81: 179-209.

Borst A. 2009. Drosophila's view on insect vision. Curr Biol 19: R36-R47.

Brennan PA, Zufall F. 2006. Pheromonal communication in vertebrates. Nature 444: 308-315.

Canteras NS, Simerly RB, Swanson LW. 1992. Connections of the posterior nucleus of the amygdala. J Comp Neurol 324: $143-179$.

Canteras NS, Simerly RB, Swanson LW. 1995. Organization of projections from the medial nucleus of the amygdala: A PHAL study in the rat. J Comp Neurol 360: 213-245.

Certel SJ, Leung A, Lin C-Y, Perez P, Chiang A-S, Kravitz EA. 2010. Octopamine neuromodulatory effects on a social behavior decision-making network in Drosophila males. PLoS One 5: e13248.

Coccaro EF, Lee R, Owens MJ, Kinkead B, Nemeroff CB. 2012. Cerebrospinal fluid substance P-like immunoreactivity correlates with aggression in personality disordered subjects. Biol Psychiatry 72: 238-243.

de la Paz Fernandez M, Chan Y-B, Yew J, Billeter J-C, Dreisewerd K, Levine J, Kravitz E. 2010. Pheromonal and behavioral cues trigger male-to-female aggression in Drosophila. PLoS Biol 8: e1000541.

Devidze N, Lee A, Zhou J, Pfaff D. 2006. CNS arousal mechanisms bearing on sex and other biologically regulated behaviors. Physiol Behav 88: 283-293.

Dierick HA, Greenspan RJ. 2007. Serotonin and neuropeptide F have opposite modulatory effects on fly aggression. Nat Genet 39: $678-682$.

Dulac C, Wagner S. 2006. Genetic analysis of brain circuits underlying pheromone signaling. Annu Rev Genet 40: 449-467.

Falkner AL, Lin D. 2014. Recent advances in understanding the role of the hypothalamic circuit during aggression. Front Syst Neurosci 8: 168.

Falkner AL, Dollar P, Perona P, Anderson DJ, Lin D. 2014. Decoding ventromedial hypothalamic neural activity during male mouse aggression. J Neurosci 34: 5971-5984.

Flavell SW, Pokala N, Macosko EZ, Albrecht DR, Larsch J, Bargmann CI. 2013. Serotonin and the neuropeptide PDF initiate and extend opposing behavioral states in C. elegans. Cell 154: 1023-1035.

Ghosh KK, Burns LD, Cocker ED, Nimmerjahn A, Ziv Y, Gamal AE, Schnitzer MJ. 2011. Miniaturized integration of a fluorescence microscope. Nat Methods 8: 871-878.

Gillette R, Huang RC, Hatcher N, Moroz LL. 2000. Cost-benefit analysis potential in feeding behavior of a predatory snail by integration of hunger, taste, and pain. Proc Natl Acad Sci 97: $3585-3590$.

Henneman E. 1985. The size-principle: A deterministic output emerges from a set of probabilistic connections. J Exp Biol 115: $105-112$.

Hess WR. 1928. Stammganglien-Reizversuche. Berichte der gesamten. Physiologie 42: 554-555.

Hess WR, Brügger M. 1943. Das subkortikale Zentrum der affecktiven Abwehr-reaktion. Helv Physiol Acta 1: 33-52.

Hirayama K, Catanho M, Brown JW, Gillette R. 2012. A core circuit module for cost/benefit decision. Front Neurosci 6: 123

Hong W, Kim DW, Anderson DJ. 2014. Antagonistic control of social versus repetitive self-grooming behaviors by separable amygdala neuronal subsets. Cell 158: 1348-1361.

Hrabovszky E, Halász J, Meelis W, Kruk MR, Liposits Z, Haller J. 2005. Neurochemical characterization of hypothalamic neurons involved in attack behavior: Glutamatergic dominance and co-expression of thyrotropin-releasing hormone in a subset of glutamatergic neurons. Neuroscience 133: $657-666$.

Inagaki HK, Jung Y, Hoopfer ED, Wong AM, Mishra N, Lin JY, Tsien RY, Anderson DJ. 2014. Optogenetic control of Drosophila using a red-shifted channelrhodopsin reveals experience-dependent influences on courtship. Nat Methods 11: $325-332$.
Insel TR, Young LJ. 2000. Neuropeptides and the evolution of social behavior. Curr Opin Neurobiol 10: 784-789.

Jennings JH, Ung RL, Resendez SL, Stamatakis AM, Taylor JG, Huang J, Veleta K, Kantak PA, Aita M, Shilling-Scrivo K, et al. 2015. Visualizing hypothalamic network dynamics for appetitive and consummatory behaviors. Cell 160: 516527.

Katsouni E, Sakkas P, Zarros A, Skandali N, Liapi C. 2009. The involvement of substance $\mathrm{P}$ in the induction of aggressive behavior. Peptides 30: 1586-1591.

Klapoetke NC, Murata Y, Kim SS, Pulver SR, Birdsey-Benson A, Cho YK, Morimoto TK, Chuong AS, Carpenter EJ, Tian Z, et al. 2014. Independent optical excitation of distinct neural populations. Nat Methods 11: 338-346.

Kohatsu S, Koganezawa M, Yamamoto D. 2011. Female contact activates male-specific interneurons that trigger stereotypic courtship behavior in Drosophila. Neuron 69: 498-508.

Koike H, Ibi D, Mizoguchi H, Nagai T, Nitta A, Takuma K, Nabeshima T, Yoneda Y, Yamada K. 2009. Behavioral abnormality and pharmacologic response in social isolationreared mice. Behav Brain Res 202: 114-121.

Kravitz EA, Huber R. 2003. Aggression in invertebrates. Curr Opin Neurobiol 13: 736-743.

Kruk MR. 1991. Ethology and pharmacology of hypothalamic aggression in the rat. Neurosci Biobehav Rev 15: 527-538.

Kruk MR. 2014. Hypothalamic attack: A wonderful artifact or a useful perspective on escalation and pathology in aggression? A viewpoint. Curr Top Behav Neurosci 17: 143-188.

Kruk M, Vanderpoel A, Lammers J, Haccou P, Olivier B. 1988. Ethopharmacology of aggression induced by stimulation in the rats hypothalamus. Aggress Behav 14: 138-138.

Kunwar P, Zelikowsky M, Remedios R, Cai H, Yilmaz M, Meister M, Anderson DJ. 2015. Ventromedial hypothalamic neurons control a defensive emotion state. Elife 4. doi: 10.77554/ eLife.06633.

Lebestky T, Chang JS, Dankert H, Zelnik L, Kim YC, Han KA, Wolf FW, Perona P, Anderson DJ. 2009. Two different forms of arousal in Drosophila are oppositely regulated by the dopamine D1 receptor ortholog DopR via distinct neural circuits. Neuron 64: 522-536.

LeDoux J. 2012. Rethinking the emotional brain. Neuron 73: 653-676

Lee H, Kim D-W, Remedios R, Anthony TE, Chang A, Madisen L, Zeng H, Anderson DJ. 2014. Scalable control of mounting and attack by Esr $1^{+}$neurons in the ventromedial hypothalamus. Nature 509: 627-632.

Lerchner W, Xiao C, Nashmi R, Slimko EM, van Trigt L, Lester HA, Anderson DJ. 2007. Reversible silencing of neuronal excitability in behaving mice by a genetically targeted, ivermectin-gated Cl-channel. Neuron 54: 35-49.

Lima SQ, Hromádka T, Znamenskiy P, Zador AM. 2009. PINP: A new method of tagging neuronal populations for identification during in vivo electrophysiological recording. PLoS One 4: e6099.

Lin D, Boyle MP, Dollar P, Lee H, Lein ES, Perona P, Anderson DJ. 2011. Functional identification of an aggression locus in the mouse hypothalamus. Nature 470: 221-226.

Lin JY, Knutsen PM, Muller A, Kleinfeld D, Tsien RY. 2013. ReaChR: A red-shifted variant of channelrhodopsin enables deep transcranial optogenetic excitation. Nat Neurosci 16: 1499-1508.

Liu W, Liang X, Gong J, Yang Z, Zhang YH, Zhang JX, Rao Y. 2011. Social regulation of aggression by pheromonal activation of Or65a olfactory neurons in Drosophila. Nat Neurosci 14: $896-902$.

Lorenz K, Leyhausen P. 1973. Motivation of human and animal behavior; an ethological view. Van Nostrand-Reinhold, New York.

Marder E. 2012. Neuromodulation of neuronal circuits: Back to the future. Neuron 76: $1-11$.

Miczek KA, de Almeida RM, Kravitz EA, Rissman EF, de Boer SF, Raine A. 2007. Neurobiology of escalated aggression and violence. J Neurosci 27: 11803-11806. 
Mundiyanapurath S, Chan Y-B, Leung AKW, Kravitz EA. 2009. Feminizing cholinergic neurons in a male Drosophila nervous system enhances aggression. Fly 3: 179-184.

Nassel DR, Winther AM. 2010. Drosophila neuropeptides in regulation of physiology and behavior. Prog Neurobiol 92: $42-104$.

Nelson RJ, Trainor BC. 2007. Neural mechanisms of aggression. Nat Rev Neurosci 8: 536-546.

Newman SW. 1999. The medial extended amygdala in male reproductive behavior. A node in the mammalian social behavior network. Ann N Y Acad Sci 877: 242-257.

Oh SW, Harris JA, Ng L, Winslow B, Cain N, Mihalas S, Wang Q, Lau C, Kuan L, Henry AM, et al. 2014. A mesoscale connectome of the mouse brain. Nature 508: 207-214.

Pfaff D, Westberg L, Kow L. 2005. Generalized arousal of mammalian central nervous system. J Comp Neurol 493: 86-91.

Salzman CD, Fusi S. 2010. Emotion, cognition, and mental state representation in amygdala and prefrontal cortex. Ann Rev Neurosci 33: 173-202.

Sano K, Tsuda MC, Musatov S, Sakamoto T, Ogawa S. 2013. Differential effects of site-specific knockdown of estrogen receptor $\alpha$ in the medial amygdala, medial pre-optic area, and ventromedial nucleus of the hypothalamus on sexual and aggressive behavior of male mice. Eur J Neurosci 37: 1308-1319.

Shaikh MB, Steinberg A, Siegel A. 1993. Evidence that substance $\mathrm{P}$ is utilized in medial amygdaloid facilitation of defensive rage behavior in the cat. Brain Res 625: 283-294.

Siegel A. 2004. Neurobiology of aggression and rage. CRC Press, Boca Raton, FL.

Siegel A, Roeling TA, Gregg TR, Kruk MR. 1999. Neuropharmacology of brain-stimulation-evoked aggression. Neurosci Biobehav Rev 23: 359-389.

Simerly RB. 2002. Wired for reproduction: Organization and development of sexually dimorphic circuits in the mammalian forebrain. Ann Rev Neurosci 25: 507-536.

Slimko EM, McKinney S, Anderson DJ, Davidson N, Lester HA. 2002. Selective electrical silencing of mammalian neurons in vitro by the use of invertebrate ligand-gated chloride channels. J Neurosci 22: 7373-7379.

Sternson SM. 2013. Hypothalamic survival circuits: Blueprints for purposive behaviors. Neuron 77: 810-824.

Stevenson PA, Dyakonova V, Rillich J, Schildberger K. 2005. Octopamine and experience-dependent modulation of aggression in crickets. J Neurosci 25: 1431-1441.

Stowers L, Holy TE, Meister M, Dulac C, Koentges G. 2002. Loss of sex discrimination and male-male aggression in mice deficient for TRP2. Science 295: 1493-1500.

Swanson LW. 2000. Cerebral hemisphere regulation of motivated behavior. Brain Res 886: 113-164.

Taghert PH, Nitabach MN. 2012. Peptide neuromodulation in invertebrate model systems. Neuron 76: 82-97.

Tinbergen N. 1950. The hierarchical organization of nervous mechanisms underlying instinctive behaviour. Sym Soc Exp Biol 4: 305-312.
Tinbergen N. 1951. The study of instinct. Clarendon Press/Oxford University Press, New York.

Toth M, Mikics E, Tulogdi A, Aliczki M, Haller J. 2011. Postweaning social isolation induces abnormal forms of aggression in conjunction with increased glucocorticoid and autonomic stress responses. Horm Behav 60: 28-36.

van Swinderen B, Andretic R. 2003. Arousal in Drosophila. Behav Processes 64: 133-144.

van Swinderen B, Andretic R. 2011. Dopamine in Drosophila: Setting arousal thresholds in a miniature brain. Proc Biol Sci 278: $906-913$.

Veening JG, Coolen LM, de Jong TR, Joosten HW, de Boer SF, Koolhaas JM, Olivier B. 2005. Do similar neural systems subserve aggressive and sexual behaviour in male rats? Insights from c-Fos and pharmacological studies. Eur J Pharmacol 526: 226-239.

von Holst E, von Saint Paul U. 1960. On the functional organization of drives. J Anim Behav 11: 1-20.

von Holst E, von Saint Paul U. 1962. Electrically controlled behavior. Sci Am 206: 50-59.

von Philipsborn AC, Liu T, Yu JY, Masser C, Bidaye SS, Dickson BJ. 2011. Neuronal control of Drosophila courtship song. Neuron 69: 509-522.

Wang L, Anderson DJ. 2010. Identification of an aggressionpromoting pheromone and its receptor neurons in Drosophila. Nature 463: 227-231.

Wang L, Dankert H, Perona P, Anderson DJ. 2008. A common genetic target for environmental and heritable influences on aggressiveness in Drosophila. Proc Natl Acad Sci 105: $5657-$ 5663.

Wang L, Han X, Mehren J, Hiroi M, Billeter J-C, Miyamoto T, Amrein H, Levine JD, Anderson DJ. 2011. Hierarchical chemosensory regulation of male-male social interactions in Drosophila. Nat Neurosci 14: 757-762.

Yamamoto D, Sato K, Koganezawa M. 2014. Neuroethology of male courtship in Drosophila: From the gene to behavior. $J$ Comp Physiol A Neuroethol Sens Neural Behav Physiol 200: 251-264.

Yang CF, Shah NM. 2014. Representing sex in the brain, one module at a time. Neuron 82: 261-278.

Yang CF, Chiang MC, Gray DC, Prabhakaran M, Alvarado M, Juntti SA, Unger EK, Wells JA, Shah NM. 2013. Sexually dimorphic neurons in the ventromedial hypothalamus govern mating in both sexes and aggression in males. Cell 153: 896909.

Zeng H, Madisen L. 2012. Mouse transgenic approaches in optogenetics. Prog Brain Res 196: 193-213.

Zhou C, Rao Y, Rao Y. 2008. A subset of octopaminergic neurons are important for Drosophila aggression. Nat Neurosci 11: $1059-1067$.

Ziv Y, Burns LD, Cocker ED, Hamel EO, Ghosh KK, Kitch LJ, El Gamal A, Schnitzer MJ. 2013. Long-term dynamics of CA1 hippocampal place codes. Nat Neurosci 16: $264-$ 266. 


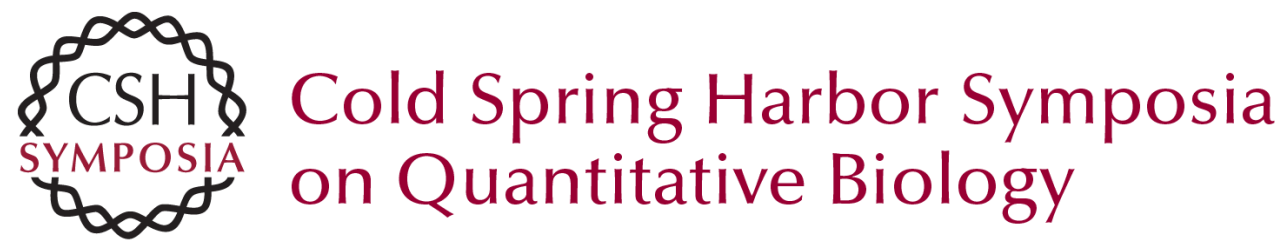

\section{Internal States and Behavioral Decision-Making: Toward an Integration of Emotion and Cognition}

Ann Kennedy, Kenta Asahina, Eric Hoopfer, et al.

Cold Spring Harb Symp Quant Biol 2014 79: 199-210 originally published online May 6, 2015 Access the most recent version at doi:10.1101/sqb.2014.79.024984

References This article cites 87 articles, 9 of which can be accessed free at: http://symposium.cshlp.org/content/79/199.full.html\#ref-list-1

License

Email Alerting Receive free email alerts when new articles cite this article - sign up in Service the box at the top right corner of the article or click here. 